\title{
UV-curable hybrid organic-inorganic membranes for the use as PEM in fuel cell
}

Oksana I. Demchyna ${ }^{a^{*}}$, Khrystyna V. Rymsha ${ }^{a}$, Mariia M. Zhyhailo ${ }^{\text {a }}$, Iryna Yu. Yevchuk ${ }^{\text {a }}$, Viktoria V. Kochubei ${ }^{\text {b }}$

a Department of Physico-Chemistry of L.M. Lytvynenko Institute of Physico-Organic Chemistry and Coal Chemistry NAS of Ukraine, Naukova Street, 3a, Lviv 79060, Ukraine

${ }^{\mathrm{b}}$ Lviv National Polytechnical University, S. Bandera Street, 12, Lviv 79012, Ukraine demchynaoksana@ukr.net

Keywords: fuel cell, proton exchange membrane, proton conductivity, organic-inorganic, hybrid nanocomposite

The series of membranes were prepared by UV-initiated polymerization of acrylic monomers (acrylonitrile AN, acrylic acid AA and potassium 3-sulfopropylacrylate SPAK) at the presence of photoinitiator (2,2dimethoxy-2-phenylacetophenone (DMPA)) and cross-linker ethyleneglycole dimethacrylate (EGDMA), and simultaneous sol-gel process in TEOS-based sol-gel system. Characterization of the obtained nanocomposites includes measurements of proton conductivity, thermal behaviuor, water/methanol uptake, free surface energy. The synthesized membranes have high proton conductivity $\left(10^{-2} \mathrm{Sm} / \mathrm{cm}\right)$ and other properties allowing to consider them as promising candidates for fuel cell application.

\section{Introduction}

Nowadays researchers are challenged to solve the environmental issues related with atmospheric pollution, green house effects and global warming Therefore they develop new types of efficient environmentally-benign energy devices. Fuel cell is a field of intense scientific activity because of promising application as environmental friendly technology. The efficiency of fuel cell can reach as high as $60 \%$ in electrical energy conversion and overall $80 \%$ in co-generation of electrical and thermal energies [1,2].
Among all other fuel cell systems direct methanol fuel cells (DMFC) which use methanol as a fuel provide many advantages over traditional energy conversion systems including high energy efficiency, reliability, modularity, simple operating conditions at a relatively low temperature, no requirement of fuel reforming process and environmentally friendly nature.

Proton exchange membrane (PEM) is a key element of a fuel cell. It plays multiple roles like charge carriers for protons, separation of the reactant gases and electronic insulation for not passing electrons through the membrane [3]. 
Protons are transported through the membrane from anode to cathode and then combined with oxygen and electron to complete the redox reaction. Consequently, electricity is generated with water being a by-product.

Despite all the achievements in the development of PEM, commercialization is still a major concern. It faces serious challenges regarding cost, durability and performance [5]. To improve the performance of DAFC, especially to reduce methanol crossover, considerable efforts have been made to modify commercial solid polyelectrolyte membrane Nafion. Considerable efforts were made to produce low cost non-fluorinated membrane. Compared to the other types of membranes, the composite ones can combine dissimilar properties of organic and inorganic materials and the components can exhibit the desired properties of both material types [4]. They also are cheaper, have a higher water uptake and high temperature range and can be recycled, what is very good for the environment. The important advantages of these membranes a low methanol permeability can be mentioned. However, there are problems associated with their chemical stability and proton conductivity because they are low compared to the other types of PEM membranes [5].

Researchers continue to carry out investigations aimed at studying the material composition of the membrane in order to increase its overall performance. A number of methods were proposed for membrane preparation. Sol-gel synthesis is one of the preferable methods as formation of the filler from sol-gel precursors usually takes place in situ what simplifies technological scheme of the process and provides component mixing at nanoscale.

Silica-based organic-inorganic hybrids have been widely used for PEM preparation [67]. Incorporation of inorganic components in a nanometre size leads to decrease in membrane swelling, reduce permeability towards methanol and improved morphological stability without compromising the proton conductivity at high sulfonation degree [8-10]. Silica-based nanocomposites are usually derived from tetraethoxysilane (TEOS) as sol-gel precursor and various polymers or monomers.

The aim of this work was to develop UV-curable cross-linked proton-conductive hybrid organic-inorganic materials on the base of acrylic monomers and silica precursors. The characterization of the synthesized materials includes measurements of proton conductivity, thermal behaviour, water/methanol uptake, determining of the free surface energy, IR spectroscopy and SEM to estimate their potential as proton conductive membranes in fuel cell application.

\section{Experimental}

Reagents for membrane preparation: acrylonitrile (AN), acrylic acid (AA), potassium 3-sulfopropyl acrylate (SPAK), 
tetraethoxysilane (TEOS), ethyleneglycol diacrylate (EGDA), 2,2-dimethoxy-2phenylacetophenone (DMPA) were purchased from Sigma-Aldrich (ACS Reagent grade) and used as received.

The polymeric part of the membrane was prepared from AN, AA, SPAK monomers using procedure described in [11]. EGDA was used as a cross-linker. The sol-gel systems based on TEOS (precursor solution was prepared separately by mixing of TEOS, ethanol, water and phosphoric acid with ratio 1:4:2:1.8 $\mathrm{mol} / \mathrm{mol}$ ) was added to the polymerizing system just before gelation (determined previously, using a rotary viscosimeter RHEOTEST 2.1 [12]) and then the whole composition was stirred for $30 \mathrm{~min}$ at $500 \mathrm{rpm}$. The feed compositions for the preparation of polymeric and hybrid polymer-inorganic membranes were as follows: AN $-0.86 \mathrm{ml}$, AA $-0.285 \mathrm{ml}$, SPAK $-0.5 \mathrm{~g}$, EGDA $-0.475 \mathrm{ml}$. DMPA $(0.04 \mathrm{~g})$ was used as a photoinitiator of the process of photoinitiated polymerization. The amount of the added solgel system for the samples was as follows: $\mathrm{S} 1-$ 0, S2 - 1 wt. $\%$, S3 - 3 wt. $\%$, S4 - 5 wt. $\%$, S5 -7 wt. $\%$.

Nanocomposite materials were obtained by UV curing technique: prepared systems were placed into glass molds, covered with glass slides to prevent the inhibiting effect of oxygen and exposed to UV light $(365 \mathrm{~nm})$ for $30 \mathrm{~min}$. UV light intensity was $14 \mathrm{~W} / \mathrm{m}^{2}$. The obtained films were washed with a large excess of acetone and water to remove unreacted compounds and dried in an oven at $50^{\circ} \mathrm{C}$ until constant weight.

The kinetic characteristics of the UVinitiated polymerization process of prepared systems were obtained by means of the method of laser interferometry. The integrated conversion $\mathrm{P}$ of the system was calculated as the ratio of contraction at a given moment to the maximum attainable one. The last was determined as the number of peaks on the interferogram.

The completeness of the polymerization process was evaluated by determining the gelfraction in the synthesized membranes. The extraction of the dissolving fraction was carried out by organic solvents in Soxhlet apparatus for $24 \mathrm{~h}$.

The estimation of the components of the surface energy of polymeric and nanocomposite films was carried out according to the OwensWendt equation:

$$
1+\cos \theta=2\left[\frac{\left(\lambda_{s}^{d}\right)^{0,5} \cdot\left(\lambda_{l}^{d}\right)^{0,5}}{\lambda_{l}}+\frac{\left(\lambda_{s}^{h}\right)^{0,5} \cdot\left(\lambda_{l}^{h}\right)^{0,5}}{\lambda_{l}}\right]
$$

where $\lambda$ is a surface tension, $\mathrm{mN} / \mathrm{m}$; the lower indices belong to a surface tension of solid $(s)$ and liquid $(l)$; the upper indices $d, h$ denote the components of the dispersion (London) and hydrogen bonding respectively; $\theta$ is a contact angle.

Sorption properties of the composite membranes were determined by measuring of the mass difference before and after swelling in 
water and methanol. Samples were dried at $50^{\circ} \mathrm{C}$ till constant weight and placed into distilled water/methanol for $24 \mathrm{~h}$. Then the samples were wiped with filter paper and immediately weighted.

The resistance of polymeric and organicinorganic membranes was measured at different temperatures by the method of impedance spectroscopy using AUTOLAB impedance spectrometer (EcoChem, the Netherlands) with FRA software equipped by thermostat. The films were sandwiched between Pt electrodes. Nyquist curves for all the samples were plot over the frequency range $10-10^{5} \mathrm{~Hz}$. Proton conductivity was calculated using the following formula:

$$
\sigma=1 / \mathrm{RS},
$$

where $\mathrm{R}$ is a sample resistance, Ohm; 1 is a sample thickness, $\mathrm{cm}$; $\mathrm{S}$ is an electrodeelectrolyte contact area, $\mathrm{cm}^{2}$.

Thermal behaviour of the films was investigated using Derivatograph Q-1500D (Paulik-Paulik-Erdey) within the temperature range of $0-400^{\circ} \mathrm{C}$ at heating rate $5^{\circ} \mathrm{C} / \mathrm{min}$.

\section{Results and discussion}

The synthesis of the series of polyacrylic-silica membranes were conducted via UV polymerization of monomers in appropriate proportions and in situ sol-gel process. Acrylic monomers (acrylonitrile, acrylic acid and 3sulfopropylacrylate potassium salt) were chosen for their rapid curing under exposure to UV light and ease handling. In particular, we used both partially soluble and hydrophilic monomers for the preparation of polymer matrix. The role of hydrophobic component was to maintain the structural and mechanical stability and limit swelling ability of the membranes, whereas hydrophilic component was introduced to ensure proton conductivity and retain water. An inorganic component was added in order to tune water management properties and thermal stability. In situ polymerization approach leads to the formation of membranes having organic and inorganic components uniformly distributed in each other.

The scheme of polymeric matrix synthesis is given in Fig. 1.

As a result of hydrolysis and polycondensation of precursor, which can be described by three overall reactions - hydrolysis (3), water condensation (4), alcohol condensation (5), silica network is formed in polymeric matrix.

$$
\begin{aligned}
& \left(\mathrm{C}_{2} \mathrm{H}_{5} \mathrm{O}\right)_{4} \mathrm{Si}+\mathrm{HOH} \rightarrow\left(\mathrm{C}_{2} \mathrm{H}_{5} \mathrm{O}\right)_{3} \mathrm{Si}-\mathrm{OH}+\mathrm{C}_{2} \mathrm{H}_{5} \mathrm{OH} \\
& \equiv \mathrm{Si}-\mathrm{OH}+\mathrm{HO}-\mathrm{Si} \equiv \rightarrow \equiv \mathrm{Si}-\mathrm{O}-\mathrm{Si} \equiv+\mathrm{HOH} \\
& \equiv \mathrm{Si}-\mathrm{OH}+\mathrm{RO}-\mathrm{Si} \equiv \rightarrow \equiv \mathrm{Si}-\mathrm{O}-\mathrm{Si} \equiv+\mathrm{C}_{2} \mathrm{H}_{5} \mathrm{OH}
\end{aligned}
$$




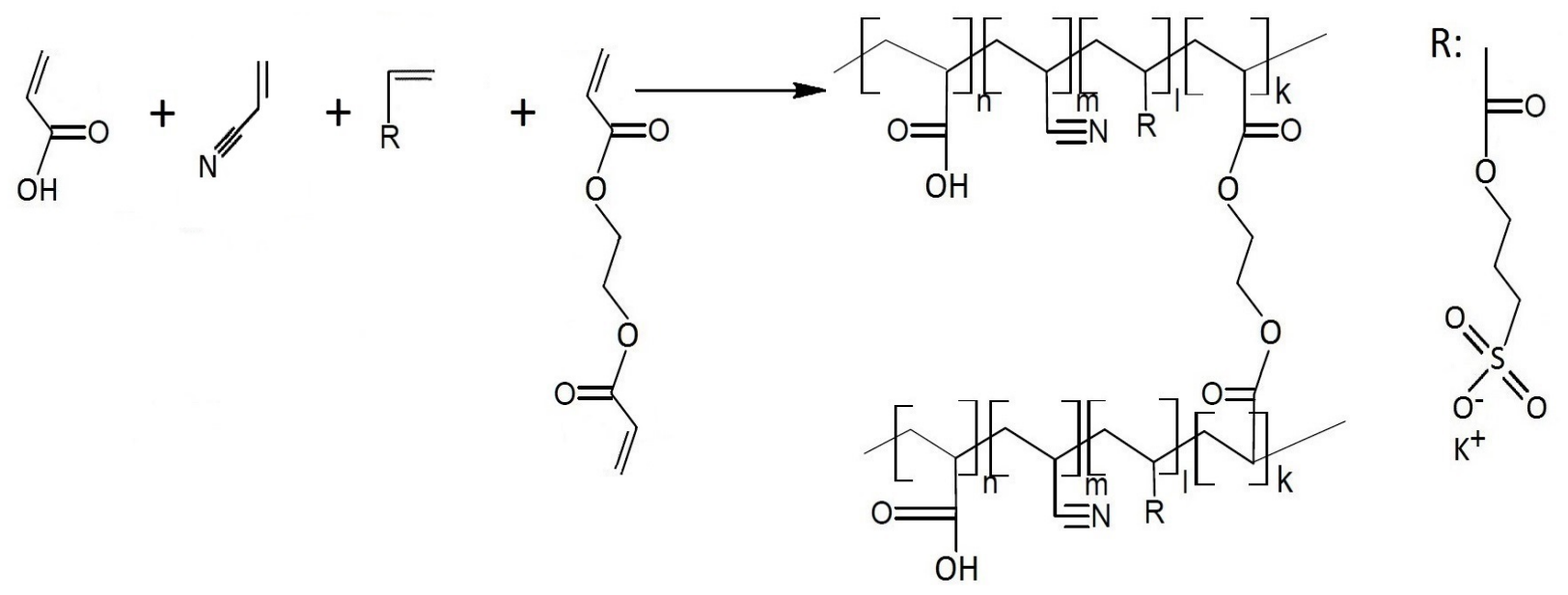

Figure 1. The scheme of synthesis of poly(AA-co-AN-co-SPAK)

Thus, interpenetrating organic-inorganic network was formed providing channels for proton transport. All the obtained membranes $(100-150 \mu \mathrm{m}$ thick) were transparent and elastic. High gel-fraction content (> 91\%) indicates the reaction of radical photoinitiated polymerization of acrylic monomers passes till high conversion, forming the cross-linked structure of nanocomposite.

Table 1. Gel-fraction of membranes

\begin{tabular}{|c|c|c|c|c|c|}
\hline Sample & S1 & S2 & S3 & S4 & S5 \\
\hline $\begin{array}{c}\text { Gel- } \\
\text { fraction, } \\
\text { wt. \% }\end{array}$ & 94,7 & 91,6 & 91,4 & 91,9 & 91,8 \\
\hline
\end{tabular}

Kinetic regularities of free radical crosslinking photoinitiated copolymerization of polymerizing systems, revealed by means of laser interferometry, are presented in Fig. 2.

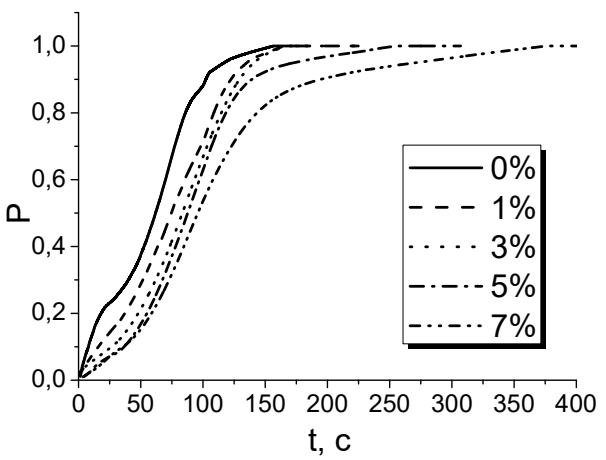

(a)

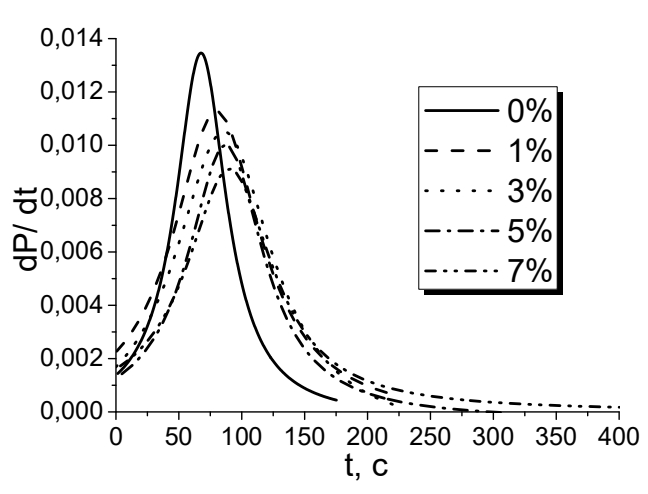

Figure 2. Integral (a) and differential (b) kinetic curves of photoinitiated polymerization of the samples S1 - S5

The obtained integral and differential curves of photoinitiated polymerization allow determining of kinetic parameters of the 
process. The maximal rate $\mathrm{W}_{\max }$ of polymerization at the acceleration stage, corresponding conversion $\mathrm{P}$ and time $\tau_{\max }$ of the achievement of $\mathrm{W}_{\max }$ were determined by the method of numerical differentiation of integral kinetic curves (Table 2).

Table 2. Kinetic parameters of the process of photoinitiated polymerization of membranes depending on their composition

\begin{tabular}{|c|c|c|c|}
\hline Sample & $\begin{array}{c}\text { Time of } \\
\mathrm{W}_{\max } \\
\text { achieve, } \mathrm{s}\end{array}$ & $\begin{array}{c}\text { Conversion } \\
\text { at } \mathrm{w}_{\max }, \mathrm{P}\end{array}$ & $\begin{array}{c}\text { Max. } \\
\text { rate } \\
\mathrm{W}_{\max }, \\
\mathrm{s}^{-1}\end{array}$ \\
\hline S1 & 68 & 0,57 & 0,014 \\
\hline S2 & 80 & 0,56 & 0,011 \\
\hline S3 & 86 & 0,52 & 0,011 \\
\hline S4 & 90 & 0,51 & 0,010 \\
\hline S5 & 92 & 0,48 & 0,009 \\
\hline
\end{tabular}

Kinetic parameters indicates the decrease in the maximal reaction rate (from $0.014 \mathrm{~s}^{-1}$ till $0.009 \mathrm{~s}^{-1}$ ) if TEOS was added. Time of $\mathrm{w}_{\max }$ reaching increases from $68 \mathrm{~s}$ for the sample S1 till $92 \mathrm{~s}$ for the sample S2. Conversion at $\mathrm{w}_{\max }$ in the investigated systems changes from 0,57 (S1) till 0,48 (S5).

The evaluation of free surface energy of synthesized polymer and polymer-inorganic materials and its components (dispersive and hydrogen) was made by the method of two liquids using the equation (1). The dispersive component includes the Van der Waals forces and other nonspecific interactions, while the hydrogen one includes hydrogen bonds.
Solving the systems of two equations (1) using the determined contact angles of the films by two liquids and the values of the components of surface tension for these liquids made it possible to determine free surface energy and its components for synthesized materials. For calculations, the values of surface tension of two liquids were used as follows: diiodomethane $-\lambda_{1}^{\mathrm{d}} 49.5 \mathrm{mN} / \mathrm{m} ; \lambda_{1}^{\mathrm{h}} 1.3 \mathrm{mN} / \mathrm{m}$; $\lambda_{1} 50.8 \mathrm{mN} / \mathrm{m}$; glycerin $-\lambda_{\mathrm{l}}^{\mathrm{d}} 30 \mathrm{mN} / \mathrm{m} ; \lambda_{\mathrm{l}}{ }^{\mathrm{h}} 34$ $\mathrm{mN} / \mathrm{m} ; \lambda_{1} 64 \mathrm{mN} / \mathrm{m}$. Numerical solution of the system of equations was made using the program Maple 9.5. The obtained values of the dispersion and hydrogen components of the surface energy and the total free surface energy of the investigated films are summarized in Table 3.

Table 3. Values of contact angles and free surface energy for polymer and hybrid membranes

\begin{tabular}{|c|c|c|c|c|c|}
\hline $\begin{array}{c}\text { Samp } \\
\text { le }\end{array}$ & $\begin{array}{c}\theta, \text { degree } \\
\mathrm{C}_{3} \mathrm{H}_{8} \mathrm{O}_{3}\end{array}$ & $\begin{array}{c}\theta, \\
\text { degree } \\
\mathrm{CH}_{2} \mathrm{I}_{2}\end{array}$ & $\begin{array}{c}\lambda_{\mathrm{s}}{ }^{\mathrm{d}}, \\
\mathrm{mN} / \mathrm{m}\end{array}$ & $\begin{array}{c}\lambda_{\mathrm{s}}{ }^{\mathrm{h}}, \\
\mathrm{mN} / \mathrm{m}\end{array}$ & $\begin{array}{c}\lambda_{\mathrm{s}}, \\
\mathrm{mN} / \mathrm{m}\end{array}$ \\
\hline $\mathrm{S} 1$ & 54.0 & 22.8 & 30.5 & 19.5 & 51.0 \\
\hline $\mathrm{S} 2$ & 53.8 & 24.3 & 34.2 & 16.4 & 50.6 \\
\hline $\mathrm{S} 3$ & 53.1 & 25.2 & 35.8 & 14.6 & 50.4 \\
\hline $\mathrm{S} 4$ & 51.6 & 28.0 & 36.0 & 13.2 & 49.3 \\
\hline $\mathrm{S} 5$ & 50.4 & 29.3 & 37.2 & 11.7 & 48.8 \\
\hline
\end{tabular}

The data show that the increasing of the added sol-gel system contact angle of wetting of the surface by diiodomethane became smaller, while if the film surface was wetted by glycerin contact angles became larger. The components of free surface energy responsible for hydrogen 
bounds formation decrease, quite the contrary the dispersive components increase. Free surface energy became smaller with sol-gel system content increasing. The insignificant decrease in free surface energy and its hydrogen component indicates the hydrophobization of the membrane surface. It may be due to the incompleteness of sol-gel process in these conditions. It is also must be taken into account that when a siloxane-based material is added to a polymer matrix due to the difference in surface energy it has the tendency to migrate to the surface [13].

Proton conductivity of the membranes is the main characteristic of the membranes as it provides their application in fuel cells. Before measurements the samples were immersed in $0.1 \mathrm{M} \mathrm{HCl}$ at room temperature to convert the membranes to $\mathrm{H}^{+}$ionic form. By means of laser interferometry resistance values were measured in a frequency range of $10-10^{6} \mathrm{~Hz}$ and the Nyquist plot (Z'vs Z'') for each sample was obtained (Fig. 3). The conductivity $\sigma$ of the samples was calculated from the impedance data.

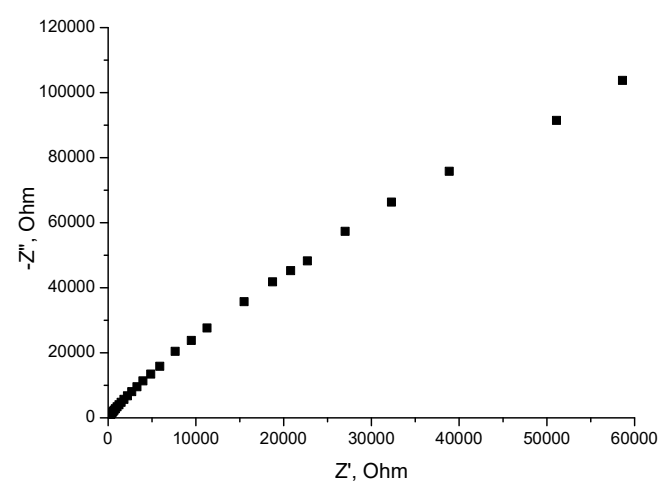

Figure 3. The Nyquist plot for the sample S1
Table 4. Proton conductivity of membranes at $20^{\circ} \mathrm{C}$

\begin{tabular}{|c|c|c|c|c|c|}
\hline Sample & S1 & S2 & S3 & S4 & S5 \\
\hline$\sigma$, & $3.53 \cdot$ & $1.37 \cdot$ & 1.01 & $9.70 \cdot$ & $9.27 \cdot$ \\
$\mathrm{Sm} / \mathrm{cm}$ & $10^{-4}$ & $10^{-2}$ & $10^{-3}$ & $10^{-4}$ & $10^{-4}$ \\
\hline
\end{tabular}

The values of proton conductivity of the obtained membranes are relatively high (the maximum conductivity value reaches $1,37 \cdot 10^{-2}$ $\mathrm{Sm} / \mathrm{cm}$, what is comparable to Nafion) and depend on the content of sol-gel system added (Table 4). High proton conductivity of ionexchange membranes is due to self-organization processes (hydrophilic/hydrophobic phase separation) resulting in the formation of the membrane matrix from hydrophobic polymer chains and clustering of hydrophilic functional groups that uptake a large amount of water. As a result, a system of pores filled with an aqueous solution containing mobile ions is formed.

At addition of sol-gel system proton conductivity sharply increases. These results are similar to the results obtained by Y. Tominaga et al. [14]. The improvement of proton conductivity in hybrid organic-inorganic membranes as compared to polymeric ones can be explained by the influence of inorganic component on ionic transport in channels. At the introduction of inorganic component the total volume of pores increases and it leads to the increasing in the volume of interconnected channels. As a result proton conductivity of membranes rises.

The capacity to retain water is a very important characteristic for proton transport 
through the membrane. The general trend observed is the increase in water uptake with the increase in sol-gel system added, that is with the increase of inorganic component of organicinorganic membranes (Fig. 4).

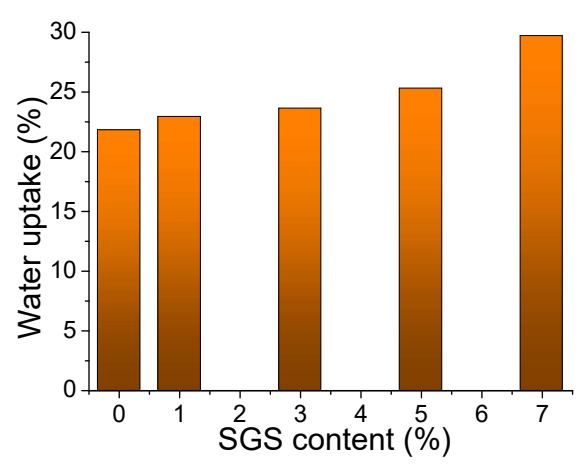

Figure 4. Water uptake vs vs SGS content

Methanol permeability is important for the use of PEM in direct methanol fuel cells (DMFC). Fig. 5 shows the dependence of methanol uptake on inorganic component in polymer-silica membranes. One can observe that methanol uptake is not significant for the synthesized membranes, what makes them promising for the use in DMFC.

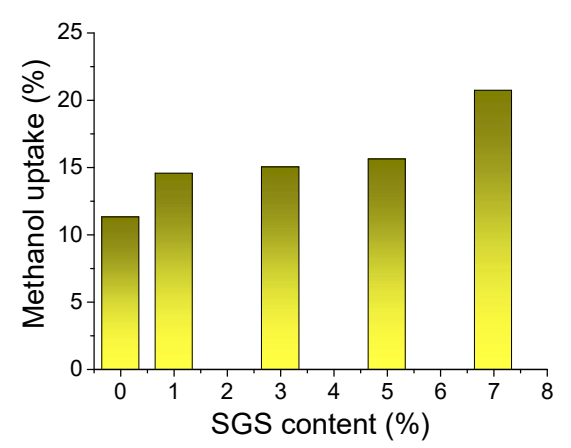

Figure 5. Methanol uptake vs SGS content
Thermal behaviour of the membranes was investigated within the temperature range of $0-400^{\circ} \mathrm{C}$. All TG, DTG and DTA curves present similar behavior. They present three regions. The first region between room temperature and $120^{\circ} \mathrm{C}$ shows the weight loss and endothermic peak associated with desorption of physically adsorbed water and residual solvents. The second region up to $270^{\circ} \mathrm{C}$ is associated with desorption of solvated water bonded to sulfo groups. The weight loss is not significant. And the next degradation step around $350^{\circ} \mathrm{C}$ and the exothermic peak can be assigned to the decomposition of sulfonic acid groups and the beginning of thermooxidative destruction of polymer matrix. This region presents significant weight loss (33 - 39\%).

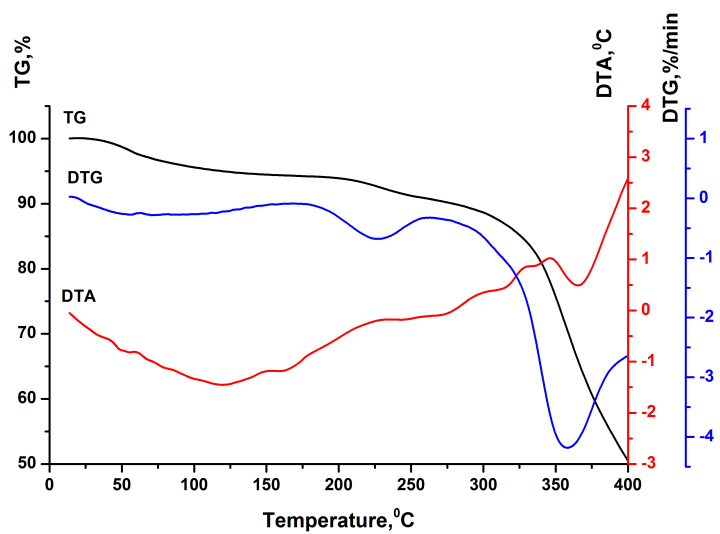

Figure 6. TG, DTG and DTA curves of the sample S1

Comparing the curves, it can be noticed that the presence of inorganic component leads to improvement of thermal stability of membranes - the beginning of the third step of membrane decomposition is shifted to the region of higher temperatures indicating the formation of Si-O-Si cross-linked structure. 


\section{Conclusions}

The simple method of preparing of polymeric and polymer-inorganic membranes was proposed. The synthesized materials demonstrate relatively high proton conductivity (comparable to Nafion $-1.37 \cdot 10^{-2} \mathrm{Sm} / \mathrm{cm}$ ) and good adsorption properties. Self-crosslinked silica network formed as a result of a sol-gel process of TEOS-based sol-gel system improves the thermal stability of PEM. The synthesized PEMs are good candidates for fuel cell application.

\section{References}

[1] Olabi A.G. Energy quadrilemma and the future of renewable energy. Energy, 2016;108:1-6.

[2] Smitha B., Sridhar S., Khan A.A. Solid polymer electrolyte membranes for fuel cell applications A review. J. Membr. Sci., 2005;259:10-26.

[3] Shamim Sh., Sudhakar K., Choudhary B. et al. Shamim S., Sudhakar K., Choudhary B. et al. A review on recent advances in proton exchange membrane fuel cells: materials, technology and applications. Adv App Sci Research, 2015;6(9):89-100.

[4] Kickelbick G. Hybrid materials: synthesis, characterization and applications, Weinheim: Wiley VCH; 2007, pp. 1-516.

[5] Ogungbemi E., Ijaodola O., Khatib F.N. et al. Fuel cell membranes - Pros and cons. Energy, 2019;172:155-172.

[6] Ibrahim A.C., Meyer M., Devautour-Vinot S. et al. A facile synthesis of proton-conducting organicinorganic membranes. J. Membr. Sci., 2014;470:189-196.

[7] Fu R.Q., Woo J.J., Seo S.J. et al. Covalent organic/inorganic hybrid proton-conductive membrane with semi-interpenetrating polymer network: preparation and characterization. J. Power Sci, 2008;179:458-466.

[8] Zhu H.G., Jones D.J., Zajac J., Dutartre R., Rhomari M., Roziere J. Synthesis of periodic large mesoporous organosilicas and functionalization by incorporation of ligands into the framework wall. Chem Mater, 2002, 14:4886-4894.

[9] Diao H., Yan F., Qiu L. High performance cross-linked poly(2-acrylamide-2-methylpropane-sulfonic acid)-based proton exchange membranes for fuel cells. Macromolecules, 2010;43:6398-6405.

[10] Yaroslavtsev A.B., Dobrovolskyy Yu.A., Shaglayeva N.S. et al. Nanostructured materials for lowtemperature fuel cells. Uspiekhi khimiyi, 2012;81(3):191220.

[11] Demydova Kh., Horechyy A., Yevchuk I., Demchyna O. The influence of the hydrophobic component content on the properties of hybrid polymerinorganic membranes. Chem. \& Chem. Tech., 2018;12(1):58-63.

[12] Zhyhailo M., Demchyna O., Demydova Kh. et al. Investigation of viscosity of sol-gel systems based on 3-methacryloxypropyltrimethoxysilane and tetraethoxysilane. Proceedings of Lviv Polytechnic National University. Chemistry, technology and application of compounds, 2018;886:58-66.

[13] Bongiovanni R., Sangermano M., Malucelli G. et al. UV curing of photoinitiator-free systems containing bismaleimides and diacrylate resins: Bulk and surface properties // Prog. Org. Coat, 53, 2005;53:46-49.

[14] Tominaga Y., Hong I.C., Asai S. et al. Proton conduction in Nafion composite membranes filled with mesoporous silica. J. Power Sources. 2007;171:530534. 